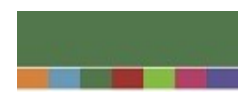

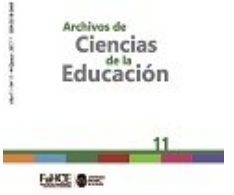

Eara o:
Archivos de Ciencias de la Educación, Vol. 11, nº 11, 2016, e023. ISSN 2346-8866

Universidad Nacional de La Plata.

Facultad de Humanidades y Ciencias de la Educación.

Departamento de Ciencias de la Educación.

\title{
Creencias epistemologicas, fuente y autoridad epistémica de estudiantes universitarios
}

\author{
College Students' Epistemological Beliefs, Source of Knowledge and \\ Epistemic Authority
}

\section{Estefania Gutierrez Cacciabue}

Universidad Nacional de Salta, Argentina | e.gutierrez.cacciabue@gmail.com

\section{PALABRAS CLAVE}

Creencias epistemológicas

Fuente de conocimiento

Autoridad epistémica

Educación superior

KEYWORDS

Epistemological Beliefs

Source of Knowledge

Epistemic Authority

College Education

\section{RESUMEN}

El presente artículo expone un estudio que examinó las creencias epistemológicas sobre la fuente y la autoridad en el conocimiento de estudiantes de educación superior, teniendo en cuenta algunos aspectos que pueden intervenir en el reconocimiento de autoridad epistémica a diversas fuentes. Se aplicó una tarea de justificación de afirmaciones a 700 estudiantes de primer año de la Universidad Nacional de Salta, y a partir de un abordaje cualitativo, se advirtió que las concepciones de los estudiantes se encontraban mediadas por cuestiones relacionadas con aspectos que trascienden lo meramente epistemológico, sugiriendo la incorporación de un enfoque contextual y situado en futuras investigaciones en esta línea.

\section{ABSTRACT}

This article presents a research of college students' epistemological beliefs, taking into account several aspects that could influence on recognition of epistemic authority to different sources of knowledge. A metodological task to justify claims was applied on 700 first-year college students at National University of Salta. From a cualitative approach, results suggested that several aspects influence on students' epistemological beliefs, sources of knowledge and recognition of epistemic authority, beyond strictly epistemological conditions. The need for future further studies about epistemology beliefs and authority from a contextual approach is underlined. 


\section{Introducción}

Dado que el conocimiento constituye el factor principal para la creación de riqueza y bienestar en el mundo y es uno de los recursos primordiales que respaldan la inclusión social, la educación -actividad a través de la cual se produce y distribuye el conocimiento- asume una relevancia peculiar y se le exige hoy una formación que posibilite a los sujetos integrar y reinterpretar las diversas fuentes de conocimiento, propiciando el desarrollo de las habilidades para emplear críticamente el caudal de recursos informativos. Lograr un pensamiento autónomo y crítico se presenta como un objetivo prioritario de la educación (Pérez Gómez, 2012).

En este contexto, resulta interesante el estudio de las creencias epistemológicas (CE) -supuestos sobre la naturaleza y los procesos de conocimiento- en tanto pueden influir significativamente en los complejos procesos de conocimiento, pensamiento y aprendizaje. Conocer las creencias que tienen los estudiantes sobre el conocimiento es un importante indicador de cómo se relacionan con el conocimiento y sus fuentes, cómo las validan, qué rol asumen y cómo es su participación en los procesos de aprendizaje.

Por tal motivo, el presente artículo expone una investigación sobre las CE acerca de la fuente y la autoridad en el conocimiento de estudiantes salteños de educación superior 1 en la cual se exploraron los supuestos de los estudiantes sobre el conocimiento y sus fuentes, indagando en qué grado les reconocen autoridad epistémica (AE), es decir, cuáles son las fuentes fundamentales a las que recurren, confían y validan.

De este modo, interesó conocer qué piensan los estudiantes universitarios sobre el conocimiento, qué fuentes consideran válidas y les reconocen $\mathrm{AE}$ y en tal sentido, qué factores pueden intervenir en ese reconocimiento, es decir, qué los lleva a elegir una fuente en detrimento de otra. Se consideró relevante indagar sobre esta problemática debido a que las CE de los estudiantes y el reconocimiento de $\mathrm{AE}$ a las fuentes podrían ser una clave interesante en relación al rol que los estudiantes asumen y el modo en que participan en sus aprendizajes y en los procesos de conocimiento, teniendo en cuenta la relevancia de estas habilidades en el contexto actual.

\section{Aportes teóricos y estado del arte}

En un mundo donde el conocimiento ocupa un papel central, y la información se acumula y circula de forma constante a través de las TIC, se requieren sujetos capaces de pensar por sí mismos y de hacer un uso consciente, crítico y reflexivo de las fuentes de información y conocimiento (Pérez Gómez, 2012; Tedesco, 1996).

En ese sentido, campos de estudio como la psicología de la educación se interesaron por la indagación de las condiciones y los aspectos que intervienen en los procesos de conocimiento de los estudiantes, vinculado a la formación de un pensamiento autónomo y crítico. Cobró así relevancia el estudio de lo que los investigadores denominaron CE, es decir, los supuestos de las personas -que son en esencia de carácter implícito- en relación al conocimiento y su adquisición, que influyen en la forma en que los sujetos se acercan y reflexionan sobre el conocimiento y sus fuentes, en su vida en general, y en los procesos educativos en particular (Hofer \& Pintrich, 2002; Pintrich, 2006; Schommer, 1990). 
Las CE parecen desempeñar un papel fundamental en las estrategias de conocimiento de los estudiantes, y pueden ser un fuerte indicador de cómo piensan, aprenden, conocen y validan la información y sus fuentes. Existen antecedentes que señalan que las CE influyen en el rendimiento académico y afectan el razonamiento, el aprendizaje, la resolución de problemas y la toma de decisiones, e intervienen en la forma en que los estudiantes abordan y evalúan la información y los problemas cotidianos (Hofer \& Pintrich, 2002; Schommer, 1990; Schommer-Aikins, 2004).

El interés por el estudio de las CE se inició con el pionero trabajo de Perry (1970), quien propuso un esquema para comprender el desarrollo del pensamiento epistemológico de los estudiantes durante su trayecto en la universidad. Posteriormente, se realizaron diversos estudios acerca de las CE, lo que ha dado lugar a modelos teóricos distintos para dar cuenta de este constructo (Belenky, Clinchy, Goldberger \& Tarule, 1968; Baxter Magolda, 1992; Hofer \& Pintrich, 2002; King \& Kitchener, 1981; Perry, 1970; Schommer, 1990; Schommer-Aikins, 2004). Entre éstos, Schommer-Aikins (2004), postula que las CE forman un sistema, lo cual implica que son múltiples y constituyen dimensiones más o menos independientes, planteando la existencia de cinco dimensiones, a saber: habilidad innata para aprender, conocimiento rápido, conocimiento simple, conocimiento seguro y fuente de conocimiento.

A pesar de la diversidad de modelos del desarrollo epistemológico los investigadores coinciden en señalar que existen en general tres grandes momentos: en una instancia denominada absolutismo, las afirmaciones del conocimiento son percibidas como hechos que pueden ser correctos o incorrectos, lo que se puede determinar directamente a partir de la contrastación con la realidad. En una segunda instancia, llamada relativismo, el conocimiento se entiende como una construcción personal no reductible a ninguna realidad concreta, sino como opiniones sostenidas por cada persona en función de sus propios criterios. La comprensión epistemológica se concreta al coordinarse ambos aspectos del conocimiento en la instancia evaluativista, asumiendo que el mismo es una construcción humana incierta, sujeta a criterios de argumentación y evidencia, que el propio sujeto es capaz de aplicar (Leal-Soto, 2010). De este modo, quienes sostienen CE que dan cuenta de epistemologías ingenuas conciben que el conocimiento reside en la autoridad, mientras que, quienes han desarrollado concepciones acerca del conocimiento como una construcción colectiva, poseerían una epistemología más sofisticada (Schommer-Aikins, 2004).

\subsection{Fuente de conocimiento y la autoridad epistémica}

Una de las dimensiones de las CE es la fuente de conocimiento, que se refiere al origen percibido del conocimiento, a su procedencia, al grado de confiabilidad que posee y la validez de sus afirmaciones. Las creencias en esta dimensión pueden manifestarse en un continuo: por un lado, los sujetos pueden percibir al conocimiento como algo dado, provisto por las autoridades -el docente, el libro, o los expertos-. Quienes sostienen creencias ingenuas en esta dimensión tienden a pensar que el conocimiento se origina fuera de sí y reside en la autoridad externa, quien puede transmitir la verdad, mientras que a partir del desarrollo del pensamiento epistemológico, el conocimiento comienza a ser percibido como producto de la evidencia empírica y el razonamiento que el propio sujeto es capaz de producir y construir, dando cuenta de creencias más sofisticadas (Hofer \& Pintrich, 2002). 
Se podría pensar entonces que los estudiantes que creen que el conocimiento se encuentra depositado en fuentes externas “autorizadas”, se limiten a aceptar las respuestas que éstas proveen, mientras que aquellos que adoptan la perspectiva de que pueden generar conocimiento mediante el propio pensamiento, puedan posicionarse de manera más activa frente a sus aprendizajes y desarrollar un uso más discriminativo y crítico de las fuentes (Pintrich, 2006; Schommer-Aikins, 2004), superando la dicotomía entre aspectos objetivos y subjetivos del conocimiento, a partir de reconocer a ambos aspectos como constitutivos de la producción de conocimiento.

En ese sentido, cobró importancia profundizar en el concepto de autoridad epistémica (AE). La autoridad constituye una propiedad relacional, comporta un significado relativo, e implica principios o atributos reconocidos, es decir, se necesita del reconocimiento, la confianza, la creencia para que algo o alguien se constituya como autoridad. Es una cuestión de vínculos atravesados por el poder, que descansan en el derecho a la legitimidad, por lo que se entiende que la autoridad no existe de hecho, sino que es una condición que se delega, a partir de otorgar a otro el derecho a ser reconocido, por lo que existe siempre la posibilidad de la resistencia y del retiro del reconocimiento (Bochenski, 1979; Gadamer, 1990; Pierella, 2014). Particularmente, la AE es la autoridad del saber referida a un sujeto que reconoce la autoridad de otro en un campo de saberes específicos; implica depositar confianza en la competencia superior y en la veracidad de otro en un determinado ámbito de conocimiento, condición necesaria para el reconocimiento de tal autoridad: el individuo acepta las proposiciones del sujeto de la autoridad porque lo considera superior en el campo del saber (Bochenski, 1979).

Bar-Tal, Raviv, Raviv \& Brosh (1991) y Kruglanski (1989) introdujeron y estudiaron este concepto en la investigación sobre las CE, bajo el supuesto de que todo conocimiento se forma sobre la base del intercambio con los otros en tanto posibles fuentes de conocimiento. La AE supone el reconocimiento por parte de los sujetos de determinadas fuentes de conocimiento -referidas a personas, entidades u objetos- en las cuales depositan autoridad, las consideran confiables.

Por tanto, explorar las CE sobre la fuente y la AE cobra relevancia ya que puede ser un indicador de los roles que asumen los estudiantes en el proceso de conocer, su relación con las diversas fuentes, y el reconocimiento de sí mismos como conocedores. Cabe agregar que son escasos los estudios sobre la autoridad en la universidad (Pierella, 2014), por lo que es interesante indagar específicamente la $\mathrm{AE}$ en estudiantes universitarios, examinando el grado de participación que asumen en la producción de conocimiento en su trayecto académico.

\section{Metodología}

\subsection{Diseño y tipo de estudio}

El presente trabajo se basó en un enfoque metodológico cualitativo (Rodríguez Gómez et al., 1996; Yuni, 2006), lógica desde la cual se intentó buscar la emergencia de conceptos y categorías de análisis que permitieran la compresión e interpretación del fenómeno estudiado. De este modo, a través de un trabajo de triangulación entre los datos recabados, los antecedentes y el marco teórico referencial de la temática abordada, se analizaron las CE de los estudiantes y el reconocimiento de $\mathrm{AE}$ a diversas fuentes. 
Cabe destacar que la elección de este enfoque respondió en parte a que diversas investigaciones de las CE han utilizado de manera preponderante estrategias cuantitativas, empleando un instrumento aplicado a nivel internacional - el SEQ (por sus siglas en inglés: Schommer's Epistemological Questionnaire), elaborado por Schommer (1990)-. Se ha advertido que en ciertas ocasiones, el cuestionario no permitió dar cuenta de la complejidad y diversidad de las creencias en función de los contextos explorados (Buehl, 2008; Hofer, 2008). Por ello, se consideró que un abordaje de tipo cualitativo permitiría apreciar en mayor detalle y profundidad las creencias de los estudiantes en relación a los significados atribuidos a las fuentes de conocimiento en tanto AE.

\subsection{Sujetos de la investigación}

A partir de un muestreo no probabilístico intencional (Baranger, 2009), se trabajó con un total aproximado de 700 estudiantes de primer año, varones y mujeres, pertenecientes a distintas facultades de la UNSa.: Humanidades, Ciencias Naturales, Ciencias Exactas, Ingeniería y Ciencias Económicas.

\subsection{Instrumento}

Se creó y aplicó una estrategia que permitió explorar las CE de los estudiantes en relación a la AE desde un abordaje cualitativo. La misma fue denominada Justificación de las Creencias Epistemológicas (JCE) $\underline{2}$, compuesta por dos afirmaciones seleccionadas a partir del SEQ (2004) $\underline{3}$, respecto de las cuales se les solicitó a los estudiantes que expresaran su acuerdo o desacuerdo y justificaran sus respuestas.

Se consideró relevante considerar las justificaciones de las respuestas de los estudiantes ya que las CE en su carácter de implícitas, pueden ser sostenidas por los sujetos de manera naturalizada, por lo que interesó explorar el origen y las razones por las cuales los sujetos expresaron acordar o no con determinadas afirmaciones sobre el conocimiento y el conocer, lo cual pudiera dar cuenta con mayor profundidad de los aspectos que intervienen en la formación de tales creencias.

En tal sentido, los ítems seleccionados permitieron indagar aspectos del conocimiento referidos a la fuente y a la autoridad en el conocimiento. Se tomaron en cuenta las expresiones textuales de los sujetos a partir de las cuales justificaron sus respuestas respecto de las siguientes frases:

- La gente que desafía la autoridad tiene demasiada confianza en sí misma.

- Cuando encuentras un concepto difícil y nuevo en un libro de texto, lo mejor es aclararlo por tu cuenta.

El primer ítem permitió explorar la creencia de los estudiantes acerca de la posibilidad o no de desafiar a una fuente "autorizada” de conocimiento. Se seleccionó esta proposición a fin de indagar más detenidamente los aspectos que intervienen en el reconocimiento o no de AE a determinada fuente de conocimiento, y lo que es aún más interesante, examinar los supuestos que operan en los modos en que el estudiante se relaciona con las fuentes de conocimiento autorizadas en su contexto 
académico, en tanto pueden actuar ciertas veces como filtros que pueden favorecer o no la adopción de una actitud más o menos desafiante por parte de los estudiantes frente a las mismas.

El segundo ítem propició la indagación acera del rol del sí mismo y la participación del estudiante como conocedor, es decir, la confianza y el reconocimiento que percibe en sus propias capacidades para producir conocimientos, lo cual permite centrar la atención en el papel que asume el estudiante, más o menos activo, en el proceso de conocer.

\subsection{Procedimiento}

El trabajo de campo de esta investigación se llevó a cabo durante los meses de abril y mayo de 2011. A fin de obtener los permisos necesarios para tal aplicación, se contactó a responsables de las facultades y profesores, solicitando la colaboración y poniendo en consideración los objetivos de la investigación. Se acordó lugar y fecha de encuentro para la administración del material a los diferentes grupos de alumnos, la cual se llevó a cabo en pruebas de papel y lápiz en situación de ambiente natural (contexto de aula) y con la presencia de la investigadora. Se informó previamente a los alumnos acerca del estudio, se agradeció su participación y se puntualizó que debían responder de forma individual y expresar simplemente lo que pensaban, dejando claro que su colaboración no afectaría su desarrollo en la asignatura. Para completar la tarea, los estudiantes precisaron de un tiempo que osciló entre los cinco y diez minutos reloj. Los encuestados participaron voluntariamente.

\subsection{Análisis de datos}

A partir de los datos obtenidos, se procedió a la elaboración de una matriz de datos conteniendo las frases objeto de estudio. Se realizó una lectura general de las mismas y comenzó el proceso de análisis mediante la categorización, triangulación y codificación de los datos. Consiguientemente, se llevó a cabo la discusión y reflexión de la información recabada a fin de describir y reconstruir los datos y generar algunas conclusiones, significando e interpretando crítica y reflexivamente los resultados (Rodríguez Gómez et al., 1996; Yuni, 2006).

La reconstrucción descriptiva de la información empírica se estructuró alrededor de un eje temático, que en este caso refirió a las CE acerca de la fuente y la autoridad en el conocimiento, y sus respectivas categorías fueron: Desafiar a la autoridad epistémica (B) y El sí mismo como fuente de conocimiento (C) (Tabla 1).

Tabla 1. Esquema de triangulación de datos cualitativos: macrocategoría, categorías y subcategorías. Fuente: de la autora

\section{CREENCIAS EPISTEMOLÓGICAS SOBRE LA FUENTE Y LA AUTORIDAD EN EL CONOCIMIENTO}

\begin{tabular}{|c|c|c|c|}
\hline Categoría & \multicolumn{2}{|c|}{ Codificación } & Sub-categoría \\
\hline $\begin{array}{c}\text { Desafiar a la autoridad } \\
\text { epistémica }\end{array}$ & A & A.1. & $\begin{array}{c}\text { Condiciones y motivos válidos para desafiar } \\
\text { a la AE }\end{array}$ \\
\hline
\end{tabular}




\begin{tabular}{|c|c|c|c|}
\hline & & A.2. & $\begin{array}{c}\text { Condiciones y motivos no válidos para } \\
\text { desafiar a la } \mathrm{AE}\end{array}$ \\
\hline \multirow{3}{*}{$\begin{array}{l}\text { El sí mismo como fuente de } \\
\text { conocimiento }\end{array}$} & \multirow[t]{3}{*}{ B } & B.1. & En interacción con otros \\
\hline & & B.2. & Independiente \\
\hline & & B.3. & Receptor de conocimiento \\
\hline
\end{tabular}

\section{Resultados}

A partir de las repuestas de los estudiantes al justificar la afirmación La gente que desafía la autoridad tiene demasiada confianza en sí misma (A. Desafiar a la autoridad epistémica), se pretendió indagar las perspectivas de los estudiantes acerca de la posibilidad o no de cuestionar la AE, profundizando en los aspectos que permiten o no desafiar la autoridad. En esta categoría emergieron dos subcategorías en función de las condiciones o motivos relacionados con esta cuestión:

A1. Condiciones y motivos válidos para desafiar a la AE: los estudiantes reconocieron ciertas condiciones, aspectos y motivos que consideraron válidos y que permiten justificar el hecho de desafiar a una autoridad. Por un lado, algunos estudiantes afirmaron que una persona que desafía a la autoridad requiere confianza y seguridad en sí misma para poder desafiar, creer en uno mimo, tener convicción, como se advirtió en las siguientes expresiones de los participantes:

- "Me parece que es así, si desafiás la autoridad es porque además de confiar en vos mismo, tenés una autoestima alta” (Alum. 5, Cs. Naturales).

- "La verdad que sí, uno para ponerse a la altura de un profesor o de una autoridad, tiene que tener mucha seguridad en sí mismo” (Alum. 5, Ingeniería).

Por otro lado, algunos estudiantes se manifestaron a favor de desafiar la autoridad cuando se trata de la defensa de los derechos e ideales de una persona:

- “Tiene confianza y además sabe lo que hace y defiende sus ideales” (Alum. 74, Ingeniería).

- "Yo creo que las personas desafían a veces a la autoridad porque creen en sus ideales y pensamiento y lo defienden” (Alum. 29, Humanidades).

Algunos estudiantes expresaron como condición fundamental para desafiar a la autoridad, tener conocimiento, que la persona conozca y sepa acerca de la temática sobre la cual pretende discutir:

- "Porque para poder enfrentar a otra persona debería estar preparada y tener conocimiento y confiar en esa sabiduría” (Alum. 30, Cs. Exactas).

- "Puede ser que si la persona sabe mucho del tema es capaz de discutir a una “autoridad” (Alum. 26, Ingeniería). 
autoridad, debe tener razones y argumentos que lo fundamenten y respalden, como se evidencia en las siguientes justificaciones de los participantes:

- "Estoy de acuerdo porque para enfrentar a otra persona debés tener los argumentos bien firmes para poder discutir tu idea” (Alum. 19, Cs. Exactas).

- "Pienso que para enfrentarse a alguien o algo hay que tener argumentos claros y concretos” (Alum. 31, Humanidades).

A. 2. Condiciones y motivos no válidos para desafiar a la AE: los estudiantes que revelaron cierta actitud desfavorable respecto a la posibilidad de desafiar a autoridad, adujeron a motivos y condiciones que consideraron no válidos, en tanto no justifican o presentan razones de peso suficiente para cuestionar a una autoridad.

En primer lugar, los estudiantes manifestaron que las personas que desafían a la autoridad creen que son superiores a los otros:

- “La gente que desafía a la autoridad se cree dios” (Alum. 22, Cs. Exactas).

- "La gente que desafía a la autoridad se siente superior a los demás y en base a eso desafía sin importar las consecuencias. No tiene humildad” (Alum. 64, Ingeniería).

Asimismo, algunos estudiantes expresaron que el hecho de desafiar a la autoridad tiene que ver con la rebeldía, es decir que quienes desafían a la autoridad son aquellas personas que "quieren llamar la atención":

- "En algunos casos puede ser, pero en otros puede ser para sobresalir o llamar la atención” (Alum. 11, Cs. Exactas).

- "No siempre la gente que desafía la autoridad por su confianza, muchas veces simplemente lo hace por llamar la atención o por rebeldía” (Alum. 116, Cs. Económicas).

En el mismo sentido, otros estudiantes destacaron que desafiar la autoridad da cuenta de una falta de educación y de respeto de la persona que lo hace, como se visualiza en las expresiones siguientes:

- “La gente que desafía la autoridad es irrespetuosa” (Alum. 7, Cs. Exactas).

- "La gente que desafía la autoridad no tiene confianza en sí misma, sino quiere hacer ver que la tiene frente a otros, es mal educada e irrespetuosa” (Alum. 113, Cs. Económicas).

Del mismo modo, algunos estudiantes expresaron que las personas que desafían a la autoridad carecen de confianza, “tienen miedo, son inseguros”, o bien lo hacen por falta de conocimiento, por ignorancia: 
- "Porque a veces lo hacen por inseguridad” (Alum. 136, Cs. Naturales).

- "No pienso del todo que tengan demasiada confianza, pienso que pasa más por la ignorancia” (Alum. 61, Humanidades).

De igual manera, algunos estudiantes manifestaron que no es correcto desafiar a la autoridad, alegando en este caso a una especie de prohibición:

- “La autoridad está para obedecerla” (Alum. 200, Ingeniería).

- “¿Desafiar la autoridad? ¿Por qué desafiar la autoridad?” (Alum. 228, Cs.

Económicas).

A partir de las repuestas de los entrevistados al justificar la afirmación Cuando encuentras un concepto difícil y nuevo en un libro de texto, lo mejor es aclararlo por tu cuenta (B. El sí mismo como fuente de conocimiento), se indagaron las creencias del estudiante acerca sí mismo como posible fuente de conocimiento. Se obtuvieron diversas respuestas de los participantes que dieron lugar a una categoría vinculada a la percepción del propio sujeto y de su rol en el proceso de conocimiento. Esta categoría permitió explorar la relación del estudiante con las fuentes externas de conocimiento y, por tanto, el papel de sí mismo como fuente de conocimiento válida. De este modo, emergieron tres subcategorías:

B. 1. En interacción con otros: los estudiantes expresaron que es posible conocer con la ayuda y en interacción con otros, ya sea profesores, expertos, pares, libros, internet, etc., en tanto fuentes de conocimiento:

- "En un principio, puede ser intentar aclararlo por cuenta propia siempre y cuando luego podamos cerciorarnos de haberlo entendido para tener la seguridad de estar en lo cierto y eso se logra con la discusión con alguien más, compañeros, profesores, etc.” (Alum. 23, Cs. Naturales).

- "Es mejor aclararlo pero con ayuda del docente si te puede brindar herramientas que no están a tu alcance, mejor” (Alum. 8, Cs. Exactas).

B. 2. Independiente: algunos estudiantes manifestaron que cuando se profundiza un concepto "por cuenta propia”, empleando las "propias palabras” para definirlo, y se procede "a la manera de cada uno”, por sí mismos, se aprende y se conoce mejor:

- “Y sí porque me gusta aprender por mí mismo” (Alum. 127, Cs. Exactas).

- "Debemos aclarar nuestras dudas con nuestra propia forma de pensar para así comprender mejor” (Alum. 49, Humanidades).

B. 3. Receptor de conocimiento: a la inversa de la subcategoría anterior, en este caso, los estudiantes manifestaron que el conocimiento "verdadero”, “correcto”, no reside ni depende del sí mismo, sino de los otros expertos, que es necesario "buscarlo en los que saben”, ya que el 
estudiante por sí sólo obtendrá “falsas respuestas”:

- "No porque puedo crearme falsas ideas, por eso es mejor consultar" (Alum. 63, Cs. Exactas).

- "Porque nunca voy a tenerlo claro sola, necesito expertos” (Alum. 129, Cs. Naturales).

- “Mejor es preguntar a alguien que sabe” (Alum. 11, Cs. Económicas).

\section{Discusiones}

Las categorías emergidas han puesto de relieve distintas posturas y perspectivas de los estudiantes respecto de la fuente y la $\mathrm{AE}$. A modo general, se pudo observar que las $\mathrm{CE}$ de los estudiantes no están fundadas en cuestiones netamente relativas al conocimiento y a la razón, sino que se entrelazan con una diversidad de aspectos que pueden influir en la formación de las creencias y mediar el reconocimiento de AE por parte de los estudiantes a distintas fuentes.

Entre las condiciones, aspectos y motivos que los encuestados consideraron válidos para desafiar a la AE (A.1, Tabla 1), emergió como requisito fundamental la confianza y seguridad en sí mismos, creer en uno mismo, tener convicción, manifestando expresiones como "para ponerse a la altura de un profesor o de una autoridad, hay que tener mucha seguridad en sí mismo”. De igual modo, expresaron que es válido desafiar a la autoridad cuando se trata de defender y luchar por los derechos e ideales de una persona, en el sentido de que quien desafía a la autoridad "tiene confianza, sabe lo que hace y defiende sus ideales”. Estas dos condiciones aparecieron con mayor frecuencia, mientras que los estudiantes destacaron en menor medida la necesidad de tener conocimientos y argumentos que fundamenten el cuestionamiento de la AE. Se puede advertir entonces que la dimensión epistemológica no es la única que se pone en juego en la relación del estudiante con las fuentes y la $\mathrm{AE}$, es decir, no basta con reconocer o no en el otro una superioridad de saberes para atribuirle AE (Bochenski, 1979) sino que se entrelazan cuestiones que tienen que ver con valores y habilidades vinculadas con la formación integral del sujeto, en términos de autoconfianza, seguridad, convicción, ideales, valores, etc.

Al respecto, es interesante destacar el concepto de autoría de sí mismo (self-authorship) propuesto por Baxter Magolda (1992; 2008) al indagar los modos de conocer de estudiantes universitarios. A partir de un estudio longitudinal, la investigadora advirtió que la mayoría de los estudiantes son dependientes de la autoridad externa respecto de qué creer, cómo identificarse a sí mismos y cómo relacionarse con otros, y fundamenta empíricamente la necesidad de formar en los jóvenes la habilidad para generar un sentido interno de sí mismos, un propio sistema interno de creencias y valores, y la capacidad de considerar -sin ser abrumados- el punto de vista de los otros. En consecuencia, sostiene que la autoría de sí constituye la base necesaria para lograr el pensamiento crítico y complejo, la capacidad de interdependencia con otros, la autonomía, etc. y expresa que el desarrollo de esta capacidad se va activando a medida que lo requiera el contexto, es decir, cuando las demandas del entorno desafían al sujeto. Pareciera pues que en la presente investigación, los propios estudiantes identificaron ciertas habilidades y cualidades -confianza y seguridad en sí mismo, valores, ideales, convicción, etc.- como requisitos fundamentales para cuestionar la AE, más allá de poseer conocimientos y argumentos desde el punto de vista epistemológico. 
Por otro lado, los estudiantes que manifestaron cierta actitud desfavorable respecto a la posibilidad de desafiar la AE adujeron a cuestiones que consideraron como no válidas (A.2, Tabla 1), en tanto no presentan razones de peso suficiente, manifestando que las personas que desafían a la autoridad creen que son superiores a los otros, en el sentido de ser "soberbios y egocéntricos” y expresaron que el hecho de desafiar a la autoridad tiene que ver con la rebeldía, que quienes desafían son aquellas personas que “quieren llamar la atención”, que es una falta de educación y de respeto de la persona que lo hace, e incluso algunos revelaron que no es correcto desafiar a la autoridad, alegando también a una especie de prohibición, lo cual, en ciertos casos, denotó aquello que es impensado por ser imposible o inadmisible.

Este desacuerdo manifiesto de los estudiantes respecto de la posibilidad de cuestionar a la AE, evidenciándolo como algo impensado y como prohibición, podría vincularse de alguna manera con la puesta en duda de la propia capacidad, en el sentido de dar por hecho que la autoridad como tal es superior al estudiante y por tanto no es posible cuestionarla. En ese sentido, algunas justificaciones de los estudiantes al respecto develaron cierta confianza a priori conferida a la fuente: los estudiantes aceptan y validan los conocimientos de una AE en algunos casos por el solo el hecho de representar "la" autoridad. Se puede inferir en estas manifestaciones que el principio de autoridad se da por sentado, admitiendo lo que una autoridad dice y sabe "porque es la autoridad” (Pierella, 2014), y en ese sentido, suscitan la reflexión en torno a la AE de una fuente de conocimiento cuando es asumida por el estudiante como algo dado, lo cual podría conducir a la aceptación acrítica de los conocimientos provistos por determinadas fuentes, por ejemplo el docente, y en consecuencia, la naturalización de esa autoridad, anulando el pensamiento propio y la participación activa en los procesos de conocer.

Lo anterior puede relacionarse con la subcategoría Receptor de conocimiento (B.3., Tabla 1) a partir de la cual se puso de manifiesto la creencia de algunos estudiantes de que el conocimiento "verdadero", “correcto”, no reside ni depende del sí mismo, ni tampoco deviene del intercambio entre diversas fuentes, sino más bien se encuentra depositado en los "otros expertos", como algo acabado que puede "buscarse en los que saben”, y que el estudiante por sí sólo puede equivocarse y “crear falsas ideas”. Esta subcategoría emergida - en consonancia con las mencionadas anteriormente (A.1 y A.2, Tabla 1)- indica que algunos estudiantes mantienen creencias más cercanas a posiciones absolutistas al concebir que el conocimiento se origina fuera de sí y reside en la autoridad externa, quien puede transmitir la verdad (Leal-Soto, 2010; Perry, 1970; Schommer, 1990).

Se advierte así que el estudiante se percibe como un receptor pasivo de conocimientos. En ese sentido, el estudio de Baxter Magolda (1992; 2008) coincide en señalar que los estudiantes ingresan a la universidad creyendo en la certeza del conocimiento y viéndose a sí mismos como aprendices que sólo reciben información que proviene de una autoridad externa, es decir que su marco de referencia son fórmulas externas que orientan sus aprendizajes, predominando en el estudiante un modo de conocimiento que carece de bases internas para producir, evaluar o cuestionar el conocimiento.

Por el contrario, otros encuestados pusieron de manifiesto la importancia de la interacción con los otros en el proceso de conocimiento y también se pudieron percibir, en algunos casos, posturas 
independientes (B.1 y B.2, Tabla 1), aludiendo a actitudes críticas con respecto a la autoridad, reconociendo la confianza de sí mismo y del pensamiento propio para aprender y conocer, dándole valor a las “propias palabras”, “a la manera de cada uno”. En ambos casos, se puede observar una cierta tendencia a adoptar una postura más integral en algunos estudiantes, reconociendo la importancia de diversificar las fuentes -incluyendo la propia voz- para lograr un conocimiento válido, lo cual estaría evidenciando en cierto modo, mayor desarrollo epistemológico -en términos de creencias más sofisticadas- como lo señalan algunos antecedentes (Belenky, Clinchy, Goldberger \& Tarule, 1968; Baxter Magolda, 1992; Hofer \& Pintrich, 2002; King \& Kitchener, 1981; LealSoto, 2010; Perry, 1970; Schommer, 1990; Schommer-Aikins, 2004).

Sin embargo, una cuestión que llamó la atención fue que, cuando el estudiante fue consultado de manera directa acerca de su desempeño y su rol en el proceso de conocimiento, reconoció la importancia de sí mismo y de sus habilidades como necesarias para conocer. No obstante, cuando se indagó sobre la posibilidad de desafiar a la $\mathrm{AE}$, fue menos común encontrar respuestas que indicaran cierta actitud independiente y crítica por parte de los estudiantes. Ello conduce a reflexionar sobre las formas de indagación utilizadas, ya que estos resultados indicarían que pueden obtenerse respuestas diversas según el modo de preguntar, especialmente en los casos en que se trata de indagar creencias o ideas de carácter implícito, como las CE.

Por otra parte, las justificaciones ofrecidas por los encuestados y, en consecuencia, las categorías emergidas, conducen a pensar en los modelos de autoridad con los que los estudiantes se han ido encontrando y los vínculos que han establecido con éstos a lo largo de su paso por distintas instancias educativas -la escuela media más recientemente-. Cuando los estudiantes expresan que “a la autoridad hay que obedecerla", que "hay que preguntarle a los que saben”, se pone de manifiesto un modelo de educación donde pareciera predominar un formato escolar específico, que desde sus orígenes ha estado asociado a logros de disciplinamiento de los sujetos (Baquero, 2009; Foucault, 1992). Sería interesante pensar cómo este formato se ha imbricado en las mentes de los estudiantes, en sus creencias en relación al conocimiento y su rol respecto de éste, de qué manera y en qué medida la posición que asume el estudiante en la relación con la AE tiene que ver con las creencias que se configuran en función de un formato escolar con fines específicos.

Es decir, aquellas concepciones del conocimiento como dado, que reside en una autoridad externa, podrían tener que ver con prácticas educativas específicas orientadas al disciplinamiento del alumnado, más que a la optimización de aprendizajes y logros cognitivos. Cabe preguntarse entonces cómo se enseña y cómo se aprende en las diferentes instituciones educativas, qué orientaciones predominan en la relación pedagógica, qué sucede cuando enseñar consiste en depositar conocimientos en “cabezas vacías”, instituyendo una vez más la diferencia entre el docente que sabe respecto a los alumnos que no saben, instalando una distancia entre un sujeto considerado activo, el formador, y un sujeto que se piensa pasivo, el educando, quien recibe la formación provista por el anterior. Esta dicotomía entre educador y educando suele ser la modalidad común en que se establece la relación entre ambos, que se inscribe en las creencias de los sujetos inmersos en la realidad educativa, naturalizando de este modo una posición pasiva frente a la autoridad en general, y frente a sus propios procesos de aprendizaje en particular.

Asimismo, se pone en evidencia que la posibilidad de atribuir o no AE no sólo tiene que ver con el 
reconocimiento en el otro de una superioridad de saberes, desde lo epistémico y racional. A primera vista, pareciera que el reconocimiento de AE está fundado en cuestiones netamente relativas al conocimiento y a la razón. Sin embargo, los estudiantes pusieron de relieve otras cuestiones que median esta atribución, más allá de lo estrictamente vinculado al conocimiento. Es decir, si un estudiante expresa que quien desafía a la autoridad “no tiene educación”, que es un "acto de rebeldía”, o que el cuestionamiento es válido en caso de defender derechos, creencias o ideales, lo epistemológico pareciera quedar en un segundo plano, o en todo caso, entrelazarse con otras cuestiones -con lo institucional, con la formación en valores, con la autoconfianza, con los modelos de autoridad reconocidos-, evidenciando que la relación del sujeto con el conocimiento y la confianza que deposita en las fuentes como a sí mismo, tienen que ver con sus concepciones tanto acerca del conocimiento como de la autoridad entendida en su carácter más general, y la relación que establecen con ésta, donde parecieran intervenir concepciones instituidas acerca del poder, de la autoridad, de lo que es válido y lo que no para un determinado contexto.

En este punto, es preciso recuperar el concepto de autoridad en el sentido de que la autoridad no existe en abstracto sino que supone un vínculo (Bochensi, 1979; Pierella, 2014) que se construye en condiciones particulares y, en el caso de los estudiantes del primer año universitario, puede estar atravesada por el trayecto educativo particular en el que se encuentran, por concepciones y prácticas de conocimiento y las formas de autoridad que han experimentado en la escuela media, las tradiciones epistemológicas, las condiciones académicas, entre otras. La autoridad no existe como cualidad dada, sino que se expresa en una relación y supone una construcción permanente que puede variar según los contextos y las épocas (Tenti Fanfani, 2006). El reconocimiento de AE por parte de los estudiantes a diversas fuentes es, por tanto, irreductible a la explicación puramente racional y epistémica (Pierella, 2014).

En ese sentido, el estudio sobre las CE acerca de la fuente y la AE devela y abre la discusión sobre ciertos aspectos que pueden intervenir en la formación de las creencias y en el reconocimiento y atribución de autoridad de los estudiantes a distintas fuentes de conocimiento, reflexionando sobre los modos en que los estudiantes conciben el conocimiento y se relacionan con los otros en sus procesos de conocer y aprender, lo cual no puede ser abordado ni reducido a un enfoque epistemológico, sino que requiere de explicaciones que reconozcan la interacción de diversidad de aspectos.

\section{Conclusiones}

El presente artículo ha expuesto un trabajo de investigación sobre las creencias epistemológicas acerca de la fuente y la autoridad en el conocimiento de estudiantes universitarios salteños.

Se evidenció de manera general que las creencias epistemológicas y el reconocimiento de autoridad epistémica por parte de los estudiantes a las fuentes no se basan únicamente en cuestiones relativas al conocimiento y a la razón, sino a diversos aspectos que median el vínculo entre los estudiantes, las fuentes de conocimiento y la autoridad epistémica. Asimismo, se advirtió en general que los estudiantes se encuentran en un momento reciente del desarrollo epistemológico, en el sentido de que develaron cierta dependencia en la autoridad epistémica quien, desde la postura de los encuestados, posee y transmite “el conocimiento verdadero” y, en consecuencia, el rol de sí mismo 
pareciera percibirse como menos relevante en la producción de conocimiento.

Estos indicadores arrojados por la presente investigación han posibilitado reflexionar sobre las concepciones que tienen los estudiantes de primer año en relación con las fuentes de conocimiento, sobre sí mismos y las posiciones y roles que podrían asumir frente a las situaciones de aprendizaje, teniendo en cuenta tanto los diferentes niveles del desarrollo epistemológico -que se han teorizado y comprobado en algunos antecedentes de este estudio-, como así también otros aspectos -como el trayecto educativo particular en el que se encuentran los estudiantes, la formación integral de los sujetos en términos de autoconfianza, las formas de autoridad con las que posiblemente se han encontrado en sus trayectos formativos, entre otros- que trascienden la dimensión epistemológica, y que podrían mediar la relación de los estudiantes con las fuentes y la autoridad en el conocimiento.

En ese sentido, es importante considerar en futuras investigaciones el modo en que la especificidad de cada contexto -académico, disciplinar, social, cultural, etc.- puede demandar, desarrollar o limitar determinadas creencias en los estudiantes. A partir de este trabajo, se ha puesto de manifiesto la necesidad de incorporar y precisar la variable contextual en el abordaje de las creencias epistemológicas y su influencia en la formación de diversas concepciones en los sujetos de la educación.

En síntesis, la investigación en esta línea puede ser reveladora de que existen supuestos que subyacen en las prácticas habituales y cotidianas en que las personas conocen y aprenden, y se relacionan con las distintas fuentes -libros, docentes, internet, etc.- que condicionan el modo y el sentido que asumirán las mismas. Por tanto, es importante que los sujetos que participan de la educación, tanto estudiantes como docentes, puedan comprender que las formas habituales de conocer, de enseñar y aprender, de relacionarse entre sí, están mediadas y atravesadas por condiciones y aspectos más allá de la dimensión epistemológica.

Tomar conciencia de ello permite avanzar hacia la formación de un pensamiento autónomo y crítico, donde los sujetos de la educación puedan repensar sus prácticas y transformarlas, generando desde la educación espacios de reflexión epistemológica que contribuya a conocer y desnaturalizar las concepciones sobre el conocimiento y los modos de conocer comunes en la cotidianeidad de tales prácticas, y de ese modo, propiciar desde el propio contexto educativo, la formación de habilidades cognitivas, epistemológicas y sociales fundamentales para que los jóvenes puedan desenvolverse en el mundo actual y participar activamente en la realidad que los rodea.

\section{Notas}

1 La investigación sobre la cual se basa este artículo forma parte de la tesis doctoral de la autora, titulada Creencias epistemológicas acerca de la autoridad en el conocimiento de estudiantes de la Universidad Nacional de Salta.

$\underline{2}$ Ello tiene como antecedente una estrategia utilizada por Pecharromán (2003), en cuya investigación se incluyeron tareas en las que se pidió a los sujetos dar respuestas a cuestiones abiertas, solicitando la justificación de la elección de cierta afirmación, obteniendo así la explicitación de las representaciones. 
$\underline{3}$ El Cuestionario Epistemológico de Schommer (1990) supone un tipo de medición de Escala Likert, que consiste en un conjunto de ítems bajo la forma de afirmaciones que evalúa el grado de acuerdo o desacuerdo de un participante respecto de una proposición dada.

\section{Bibliografía}

Baquero, R. (2009). Desarrollo psicológico y escolarización en los Enfoques Socio Culturales: nuevos sentidos de un viejo problema. En: Avances en Psicología Latinoamericana, 27(2), 263-280.

Baranger, D. (2009). Construcción y análisis de datos. Introducción al uso de técnicas cuantitativas en la investigación social. Posadas: Editora Universitaria de Misiones.

Bar-Tal, D., Raviv, A., Raviv, A. \& Brosh, M. E. (1991). Perception of Epistemic Authority and Attribution for its Choice as a Function of Knowledge, Area and Age. European Journal of Social Psychology,_21(6), 477-492.

Baxter Magolda, M. B. (1992). Knowing and Reasoning in Collage. Gender-related Patterns in Students'Intellectual Development. San Francisco: Jossey-Bass.

Baxter Magolda, M. B. (2008). The Evolution of Self Authorship. En: M. S. Khine (ed.), Knowing, knowledge, and beliefs: Epistemological studies across diverse cultures (pp. 45-64). New York: Springer.

Belenky, M. F., Clinchy, B. M., Goldberger, N. R., \& Tarule, J. M. (1986). Women's Ways of Knowing: The Development of Self, Voice and Mind. Nueva York: Basic Books.

Bochenski, J. M. (1979) ¿Qué es la autoridad? Barcelona: Herder.

Buehl, M. M. (2008): Assessing the Multidimensionality of Student's Epistemic Beliefs Across Diverse Cultures. En: Khine, M. S. (Ed.), Knowing, Knowlegde, and Beliefs: Epistemological Studies across Diverses Cultures (pp. 65-112). New York: Springer.

Foucault, M. (1992). Vigilar y castigar. Nacimiento de la prisión. Madrid: Siglo XXI.

Gadamer, H. G. (1990). Verdad y Método. Salamanca: Sígueme.

Hofer, B. K. \& Pintrich, P. R. (Eds.) (2002). Personal Epistemology. The Psychology of Beliefs about Knowledge and Knowing. Mahwah, Nueva Jersey: Erlbaum.

Hofer, B. K. (2008). Personal Epistemology and Culture. En: Khine, M. S. (Ed.), Knowing, Knowlegde, and Beliefs: Epistemological Studies across Diverses Cultures (pp. 3-23). Nueva York: Springer.

King, P. M. \& Kitchener, K. S. (1981). Developing Reflective Judgment: Understanding and Promoting Intellectual Growth and Critical Thinking in Adolescents and Adults. San Francisco, Estados Unidos: Jossey-Bass.

Kruglanski, A. W. (1989). Lay Epistemics and Human Knowledge: Cognitive and Motivational Bases. Nueva York, Estados Unidos: Plenum. 
Leal-Soto, F. (2010). Creencias epistemológicas generales, académicas y disciplinares en relación con el contexto. Universitas Psychologica, 9(2), 381-392.

Pecharromán, I. (2003). Teorías epistemológicas implícitas en diferentes dominios: influencia de variables relacionadas con la instrucción (tesis doctoral). Universidad Autónoma de Madrid, Madrid.

Pérez Gómez, A. I. (2012). Educarse en la era digital. Madrid: Morata.

Perry, W. G. (1970). Forms of Intellectual and Ethical Development in the College Years: A Scheme. San Francisco: Jossey-Bass.

Pierella, M. P. (2014). La autoridad en la universidad. Vínculos y experiencias entre estudiantes, profesores y saberes. Rosario: Paidós.

Pintrich, P. R. (2006). Las creencias motivacionales como recursos y restricciones para el cambio conceptual. En: Schnotz, W., S. Vosniadou, y Carretero, M. (Comps.), Cambio conceptual y educación (pp. 53-86). Buenos. Aires: Aique.

Rodríguez Gómez, G., Gil Flores, J. y García Jiménez, E. (1996). Metodología de la investigación cualitativa. Málaga: Aljibe.

Schommer, M. (1990). Effects of Beliefs about the Nature of Knowledge on Comprehension. Journal of Educational Psychology 82(3), 498-504.

Schommer-Aikins, M. (2004). Explaining the Epistemological Belief System: Introducing the Embedded Systemic Model and Coordinated Research Approach. Educational Psychologist, 39(1), 19-29.

Tedesco, J.C. (1996). La educación y los nuevos desafíos de la formación del ciudadano. Nueva Sociedad, 146, 74-89.

Tenti Fanfani, E. (2006). Viejas y nuevas formas de autoridad docente. Revista Todavía 7, 1-4.

Yuni, J. y Urbano, C. (2006). Técnicas para investigar 1, 2 y 3. Córdoba: Brujas. 